\title{
Comunicação alternativa no Brasil: Pesquisa e Prática
}

\author{
Michele Oliveira da SILVA ${ }^{1}$
}

NUNES, Leila Regina d'Oliveira de Paula; PELOSI, Miryam Bonadiu; GOMES, Márcia Regina (Org). U m retrato da comunicação alternativa no Brasil: relatos de pesquisas e experiências.

Em uma sociedade onde as interações sociais se estabelecem predominantemente pela fala, pessoas que, por diversos fatores, não apresentam a oralidade ou têm al terações que os impossibilitam de adquirir uma comunicação funcional, podem ter suas relações sociais e pessoais restringidas.

Em cada caso, a ausência da fala pode vir acompanhada de alterações sensoriais, motoras e/ ou cognitivas, que contribuem para que a pessoa tenha dificuldades em estabelecer outro tipo de comunicação compreensível, seja por gestos, por sons ou por expressões faciais.

Nessecontexto, o livro U m R etrato da Comunicação A Iternativa no Brasil: relatos de pesquisas eexperiências (volumel ell), contendo trabal hos apresentados no I Congresso Internacional de Linguagem e Comunicação da Pessoa com Deficiência eno I Congresso Brasileiro de Comunicação A Iternativa- ISAAC Brasil, torna-se um grande referencial teórico para todos aqueles que têm como meta garantir, por meio da comunicação alternativa, o acesso desses indivíduos aos contextos sociais.

A forma didática em que os textos foram escritos permite o entendimento não só para especial istas da área, mas, para todos quetêm interesse em conhecer as inúmeras possibilidades existentes para que a comunicação alternativa seja estabel ecida.

Como o próprio título sugere, o livro apresenta o que tem sido feito dentro do campo da comunicação alternativa no contexto brasileiro, trazendo estudos realizados por diferentes profissionais, como pedagogos, fisioterapeutas, terapeutas ocupacionais, fonoaudiólogos, musicoterapeutas, dentre outros.

\footnotetext{
${ }^{1}$ Mestranda do Programa de Pós-graduação em Educação da Faculdade de Filosofia e Ciências da Unesp campus de Marília - miilly21@yahoo.com.br
} 
Além disso, é possível observar pesquisas científicas realizadas em diferentes contextos, como em jogos lúdicos, atividade de ensino, atividades de recreação, sempre enfatizando a parceria desses profissionais com as famílias e com a sociedade em geral.

Dentro desses enfoques, o livro oferece um conteúdo vasto de experiências em diferentes ambientes, como na escola, na clínica, na instituição e em muitos outros locais, demonstrando que a comunicação alternativa pode garantir mel hores oportunidades de acesso à vida social eà vida familiar.

Enfatiza ainda, outros benefícios alcançados pelos usuários da comunicação alternativa, a partir da aquisição de uma comunicação funcional. Como, por exemplo:

- Melhora da auto-estima;

- Maior independência para realização das atividades;

- Aumento do poder de decisão;

- Aumento do número de interlocutores;

- Melhor qualidade de vida para o sujeito e para seus pares.

Enfim, mesmo tentando resumir em palavras-chave a riqueza do conteúdo dos artigos, seria impossível descrever os inúmeros dados que as pesquisas relatam e que contribuem para a ampliação do uso da comunicação alternativa.

Ademais, o leitor terá a oportunidade de fazer uma breve revisão histórica, além de conhecer as diversas técnicas, o uso da tecnologia assistiva, os recursos, as avaliações, e tantos outros instrumentos e metodologias utilizadas atualmente para o planejamento, adequação e escolha do tipo de comunicação mais indicada às especificidades de cada sujeito.

Por fim, as experiências pessoais relatadas pelos próprios usuários da comunicação alternativa, e tantas outras, relatadas por sujeitos que participaram desse processo, renovam as forças dos profissionais que lutam para que todos tenham acesso a uma vida digna, compartilhando os ambientes sociais, independentes de suas características. 